\title{
16. Family behaviour of migrants
}

\author{
Gunnar Andersson
}

\section{INTRODUCTION}

Research on the family behaviour and family dynamics of migrants is a cross-cutting theme. Many of the broader features of family behaviour (such as intergenerational relationships or family diversity) are relevant in the study of migrant family behaviour. There are also many themes that are specifically relevant to migrants. The study of different aspects of migrant behaviour is a promising avenue of research, with the potential to uncover complexities and relationships that are not as easily tracked when studying less mobile populations. Studies on the family behaviour of migrants can take both a population and an individual-level perspective. Migration events and family dynamics have an impact on societies at large, and are influenced by contextual factors in both the societies the migrants come from, and the societies where they reside at any given point in time. Migration and family demographic events are intertwined in the life courses of individual actors. What makes the family behaviour of migrants so intriguing is that their life courses unfold over time across two or more spatial contexts, under the influences of all the social factors that are intrinsic to those respective contexts. This contribution begins with a population-level perspective, and considers the impact of migration on population change in Europe. It proceeds with a section that introduces a life course perspective on migration and family demographic behaviour, followed by a section that examines the many multi-level factors that may contribute to family demographic behaviour and family demographic change among migrants. The subsequent section focuses on family formation and family dissolution, and the section after explores the fertility of migrants. The contribution concludes with a discussion of data issues in relation to the fertility of migrants, and some of the challenges that arise in studies of the demographic behaviour of mobile individuals. The focus of the contribution is on migrants, with only limited attention being given to individuals who have a migration background, but are not themselves migrants.

\section{MIGRATION AND DEMOGRAPHIC CHANGE}

Most migration events occur when women and men are in their 20s. This holds for short-distance domestic geographical moves, as well as for migration across national borders. Migration is closely related to the process of family formation and of getting established as an adult, it is comprised of events related to leaving the parental home, establishing an independent household, union formation and dissolution, marriage and divorce, and becoming a parent. Migration events typically precede, happen in tandem with, or follow shortly after these family demographic events. At the population level, migration contributes to increases or decreases in population size, and to the rejuvenation or ageing of population age structures, either directly or indirectly. As the age schedule of migration peaks in the early to mid-20s, immigration adds people at relatively young ages to the receiving areas and subtracts people at the same 
ages from the sending areas. Migration thus has the largest impact on population structures at ages that are also dense with events related to family formation, childbearing, and labour force participation. Regions that receive immigrants add not only young adults, but also a number of children born shortly after the immigrants arrive; while the opposite pattern occurs in regions that produce out-migrants. These dynamics are fuelled by the fact that age-specific migration rates peak at lower ages than those of age-specific fertility. Migration is more likely to precede family formation and childbearing than the other way around, and is usually undertaken in the early stages of the process of getting established as a young adult.

The size and the composition of populations in Europe with a migration background are produced by the past history of migration between regions and countries in Europe, as well as by the past history of immigration from and emigration to continents outside Europe. During and in the wake of the demographic transition in the nineteenth and early twentieth centuries (Notestein 1945), the size of the population in Europe increased exponentially, and the continent produced huge numbers of emigrants to America and other parts of the world. Calculations for a set of countries in Western Europe show that the direct and indirect effects of long-term international migration on population size is only now on the verge of producing any visible surpluses compared with the hypothetical situation of no international migration from and to these European countries during the last few centuries (Murphy 2016).

Europe as a whole went from being a net emigration region to an immigration region after the end of World War II. The transformation into a migration destination was most pronounced and took place earlier in Northern and Western Europe, while Southern Europe contributed to intra-European South to North migration for several decades. At the same time, several of the previous colonial powers of Europe received migrants from their past spheres of influence outside of Europe. Due to the barriers of the Iron Curtain of Europe, there was little East to West migration until the fall of communism in 1989. The latter type of migration has subsequently gained in importance. During the last few decades, most countries in Southern Europe went from being emigration areas to being destinations for migrants from both Eastern European and non-European countries. Enlargements of the European Union (EU) and the related freer movement of people within Europe have helped to make intra-European migration easier than it was before, and have also made the distinction between domestic and international migration less salient. All of this migration history (e.g., Castles et al. 2013) has produced and keeps producing migrant populations in Europe. Many of the processes that link migration and family behaviour have similar logics, regardless of whether the migration occurs domestically between regions of a country or across national borders. However, when migration occurs across longer distances - whether geographical or social - it involves more contrasts, ruptures, opportunities, and challenges for the individuals who migrate, and for the contexts in which they are embedded.

Thus, it is clear that migration contributes to a wide range of dimensions of demographic and social change in both the migrants' regions of origin and their destinations. The migrants themselves contribute to the ongoing family and demographic changes in the societies in which they live. Their origin and destination areas may be at different stages of the 'demographic transition', with entirely different fertility regimes. Figure 16.1 illustrates this pattern by displaying the fertility developments of France and Germany as representative of two leading countries of destination in Europe, and contrasting these developments with those in Morocco and Turkey, which used to be prime countries of origin for these destination countries. The figure shows that the Turkish and Moroccan migrants of the 1960s came from high-fertility 
countries, which is no longer the case for their counterparts who have migrated since the turn of the century. In terms of their demographic contributions, we note that recent migrants from outside of the EU come in part from countries with higher fertility, but also from contexts with similar or even lower fertility than the levels that prevail in many migration destinations in Europe. In fact, there is an increasing shift towards migration from destinations with low fertility. Migrants within Europe often come from countries with low or very low fertility, and move to destinations in Northern and Western Europe with higher aggregate levels of fertility. This pattern is represented in Figure 16.1 by the example of Poland. In these cases, migration contributes to ongoing processes of population rejuvenation by adding young migrants to the populations in Northern and Western Europe, as well as to population ageing and decline by subtracting young people from the populations in Central and Eastern Europe.

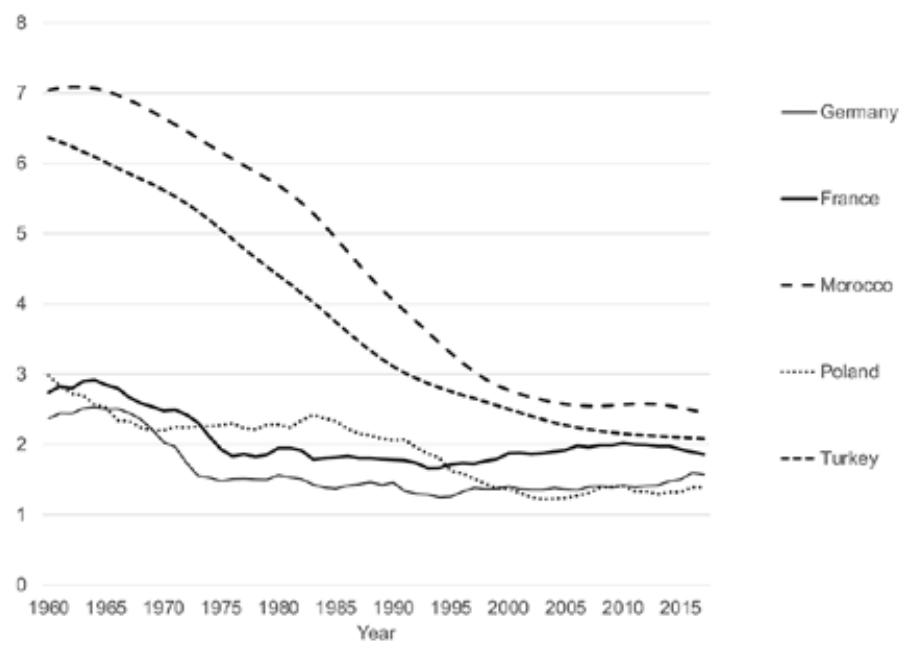

Source: World Bank (2019).

Figure 16.1 Total fertility rate in typical destination countries (Germany and France) and selected countries of origin (Turkey, Morocco, and Poland), 1960-2017

\section{LIFE COURSES ACROSS ORIGIN AND DESTINATION CONTEXTS}

There is a large body of sociological research that has applied a micro-level perspective to the study of migrants, and to the dynamics that shape their life courses and the family behaviours that occur at different life course stages. A similar perspective is used in the demographic logics of analyses in which longitudinal duration data are analysed with statistical event-history techniques (see Konietzka and Kreyenfeld in this volume). As stated above, what makes the study of migrants so intriguing is that their life courses evolve over different social and geographical contexts, which allows for more refined research on how different contextual factors linked to places of origin and destination relate to individual behaviour; and on how the migration process itself intervenes in the processes of family formation, family dissolution, and childbearing. These approaches can also be easily linked to migration theory, 
which discusses the role of push (from origin) and pull (from destination) factors in migration decisions, and the effects of the many intervening factors that stem from the migration process itself (e.g., Lee 1966). Studies on the family behaviour of migrants need to consider both preand post-migration circumstances, as well as the intervening process of migration. In addition, these studies need to consider the various multi-level dimensions of individual characteristics (with micro-level data), social networks (in meso-level data), and contextual factors related to culture, institutional factors, and broader social change (as measured in macro-level data) in relation to individual behaviour.

The role of contextual factors - as manifested by welfare states, social policy regimes, social citizenship, business cycles, political climate, demographic regimes, local family systems, family law, religion, culture, and social norms in relation to family behaviour - are all factors to consider in any sociology of the family, and are discussed in many other chapters of this handbook. Indeed, Europe provides an ideal laboratory for comparative family demographic research, with its huge variation at the national and sub-national levels in different aspects, dimensions, and combinations of these factors. With its many refined sets of comparative contextual and individual-level data infrastructures, contemporary Europe is perhaps the most rewarding region of the world to study with any research design that involves comparative family demographic research. The study of migrants offers additional possibilities for sociological and family-demographic research. This is still a largely untapped reservoir of research opportunities. Migration between countries in Europe multiplies the many contextual factors that are worth considering when factors related to the origin as well as to the destination combine in shaping individual behaviour. Migration from outside Europe brings influences from new contexts of origin that cover the entire spectrum of worldwide family systems and patterns of family demographic change, and all other contextual factors that may be at play in shaping migration, family behaviour, and onward and circular migration. A small fraction of migrants may come from high-fertility regimes that have yet to experience the demographic transition and its fertility decline. Others may come from low-fertility regimes, but from societies that have experienced less of the individualisation processes that are assumed to contribute to contemporary family change in Europe. Through these migrants, all the world's and all of Europe's family systems are brought together in a single analytical framework.

\section{FAMILY DEMOGRAPHIC BEHAVIOUR OF MIGRANTS: CONTEXTUAL FACTORS AND INDIVIDUAL BEHAVIOUR}

Family demographic life course research typically considers a standard range of individual-level factors related to different demographic and socio-economic characteristics of the study subjects. Some of these factors are time-varying, while others are fixed in time. In sociological research, factors related to norms, social interactions between individuals, and the broader social context are often considered. When studying migrants, scholars seem to focus on factors related to culture to a greater extent than they do when studying national native populations. In some cases, analysts appear to perceive migrants as having more cultural traits than their own ancestral population. The role of childhood socialisation into different modes of norms and behaviours is almost always stressed when migrants are studied. Socialisation is perceived as having occurred in and being influenced by the migration origin context, while different institutional and labour market factors are frequently seen as influential in the migration-destination 
context, together with factors that may indicate a process of acculturation. Recent extensions of research also consider the role of transnational networks and transnational space, and thus have the capacity to take a more nuanced approach to these issues (Glick 2010, see also Merla et al. in this volume).

The role and the influences of different family systems in migration origins and destinations within Europe and beyond merit particular attention when the family behaviour of migrants is studied. In Europe, the church historically had a decisive impact by breaking down the influences of clan systems and the importance of lineages in family decisions (e.g., Goody 1983). This was done by placing severe restrictions on, for example, consanguineous marriages. The purpose was to strengthen the power of the church, but it also had long-lasting effects on family systems that stretched into later processes of family nuclearisation and increased individual autonomy. In many other parts of the world, family systems are built more decisively on the logics of lineages. In some cases, clan systems act as crucial factors in family-related behaviour and family demographic decisions (Goode 1963, 1993). However, there is also considerable variation in family systems within Europe, both historically and in contemporary family demographic change (see Ehmer in this volume).

The characteristics of labour markets and welfare states may have even more decisive effects on the family behaviour of migrants than of those individuals who are better established in a given society. Immigrants can sometimes be seen as being at the margins of society (Bledsoe 2004). The social policies of countries differ in the degree to which they include new residents, whether citizens or non-citizens. For migrants and non-migrants alike, policies that are linked to the marital status of an individual may affect socio-demographic outcomes to a greater extent in conservative welfare states than in the universalistic welfare regimes of Northern Europe (Neyer in this volume). Moreover, policies that regulate the right to marry someone from another country may differ both between countries and across time, and can have a particularly large impact on people with current or prospective migrant status. In the EU, some of these policies are harmonised, which may produce barriers to marriage-related migration from outside the EU, but facilitate family connections within the EU. Still, family law is a complex arena with the potential to create obstacles in family demographic processes across different countries within the EU as well.

Clearly, economic factors play an important role in migration, family formation, childbearing, and other aspects of family dynamics. This is the case for factors that can be measured at the individual level, as well as for more structural factors that belong to the contextual setup of different migration origins and destinations (e.g., Massey et al. 1993). Again, to understand these dynamics, it helps to consider the transnational nature of different economic relations. It is beyond the scope of this chapter to provide an account of different theories that characterise migrants and non-migrants as economically rational actors when making family, work, and other life course decisions. However, most researchers do consider a wide range of (socio-) economic factors in their research designs. To some extent, recent changes in international migration have maintained a bifurcation of the economic dynamics of migration into different segments; for example, of low-paid service workers and high-paid professionals (e.g., Castles et al. 2013). The family considerations at different levels of social stratification may differ substantially.

The role of contextual factors in individual behaviour is often mediated by interactions in different social networks to which individuals belong, and is studied at the meso level in researchers' analytical designs. In the case of migrants, these networks often stretch across 
regional and national borders. Cultural factors may matter for family behaviour, and culture can be viewed as something that is maintained and recreated within the realms of social networks (Bachrach 2014). For migrants, family and community networks help maintain their ties to a multitude of locations across space and time (Boyd 1989).

As migrants form new families, it becomes necessary to consider the characteristics of newly created couples. For example, the partners may have different migration backgrounds, or one partner may have no migration background at all. Different modes of union formation mean that different types of individual-level and contextual factors need to be considered. Another line of research focuses on the children of immigrants in different contexts; the so-called 'second generation'. These individuals are not migrants themselves, but have a migration background through their parents. Given the more extended migration histories in many countries in Europe, studying this population has become increasingly important. Many of the hypotheses applied to immigrants do not apply to the second generation. As there are no own individual migration trajectories to account for, the focus is on issues of early life socialisation, perhaps in relation to segmented assimilation in communities of local minorities; and to the structural constraints that children of migrants may face in the society in which they grow up. This research is valuable, as it provides insight into processes of intergenerational relations and the more long-term processes of social change that may follow in the wake of international migration. Some research on the fertility of these second-generation populations in different countries in Europe has shown that their fertility is surprisingly low (Andersson et al. 2017a; Kulu et al. 2017), while other findings report that fertility levels remain high for specific sub-groups in the second generation (Kulu and Hannemann 2016). Taken together, these findings suggest that the scope for the long-term fertility-enhancing effects of international migration at the population level is very limited.

\section{FAMILY DYNAMICS, MARRIAGE, AND DIVORCE}

The family dynamics of migrants may be influenced by factors related to their regions of origin, as well as to their (re-)current destinations. Research on marriage and divorce among international migrants in Europe has shown that these patterns vary widely, even within a given country context. These differentials seem to largely reflect behaviours that are prevalent in the migrants' countries of origin, and thus provide some support for the claim that early life socialisation plays a role in maintaining the norms that underlie different family systems, and the prominence of marriage in relation to non-marital cohabitation. For example, Andersson et al. (2015) found that the marriage, divorce, and re-marriage rates of immigrants in Sweden are sometimes higher, and are sometimes lower than those of the native population of ancestral Swedes. In many cases, these differentials can be connected to patterns in the migrants' countries of origin. For example, the high rates of marriage, divorce, and re-marriage observed among migrants from regions of Africa and the Arab Mideast reflect a high degree of 'churning'. Meanwhile, patterns of early and stable marriage are found among migrants from Turkey, and late marriage and low divorce risks are observed among migrants from Southern Europe. Hannemann et al. (2020) presented similar findings in a cross-country study of partnership dynamics among immigrants in four European countries. They found, for example, high rates of marriage formation and low divorce risks among migrants from South Asia, and the opposite pattern for migrants from the Caribbean in the United Kingdom. Their cross-country 
comparative study adds analytical depth by demonstrating that the country context in Europe seems to matter as well; the authors highlighted that different types of migrants in Spain seem particularly geared towards marriage, just as native people in this country are. In some study populations, the observed patterns sometimes fail to conform to expectations based on theories of country-specific early life socialisation. In such cases, researchers may seek explanations in theories of behavioural adaptation, whereby norms and attitudes to marriage and its alternatives are expected to change as migrants are exposed to new normative and behavioural contexts (e.g., Kahn 1988). Marriage is a symbolic status marker (Cherlin 2009), and norms are indeed likely to matter in nuptial behaviour. Such norms may be adjusted more rapidly by migrants than by others, as migrants are exposed to a wider array of contexts, to networks that stretch across space and time, and to networks that may be embedded in different segments of a given population (Portes et al. 2005). However, other explanations for differences in observed behaviour are also helpful. In many cases, such differences may be explained by different selection mechanisms, as migrants from a given country rarely represent the average of the people who reside in their country of origin. If selective migration is produced along dimensions that can be tracked by observable characteristics, then differentials in behaviour and outcomes can be linked to those factors.

It is also instructive to pay attention to the many instrumental and structural factors that support different types of family behaviour in a given context, and that may have similar or different logics for migrants and native people. Marriage can, for example, be perceived as offering a more secure status in a new and less familiar context, and may thus be seen as more attractive by many migrants than it is by non-migrants. On the other hand, in their new context, migrants may feel more free to resist normative pressures to conform to ascribed modes of family-related behaviour. For some migrants, however, the civil status of marriage is imperative for securing legal status in their new context (Bledsoe 2004). Marriage and family reunification are common motives for migration, and couple formation across an external EU border often requires that a marriage is registered. In other cases, marriage and migration are highly interlinked processes, even when migration takes place between different regions of a country or between countries within the EU (e.g., Haandrikman 2014). Thus, family (re)unification events produce higher rates of marriage formation for many groups of migrants in a given context. This may be visible in the marriage rates of male migrants, particularly in situations in which a male pioneer is later joined by his female partner in couple-related migration. It is also more common for a person with a migration history than for a native individual to marry someone from abroad. Some of the literature on the family behaviour of migrants focuses explicitly on the role of intermarriage, and the extent to which different groups of migrants are likely to marry endogamously (i.e., with someone from their own country of origin) or exogamously (i.e., with someone from their new country of residence) (Dribe and Lundh 2011). While intermarriage is often seen as a marker of social integration into the new context, it can also be considered a marker of how open the context is to new entrants.

Divorce risks are often higher for migrants than for non-migrants with similar characteristics (Andersson et al. 2015). To some extent, divorce risks are influenced by norms that support or hinder the initiation of divorce. In a new context, normative pressures to stay married may be felt less strongly. But divorce risks may also increase because migration is often a stressful process, and because it opens up entirely new and often unexpected life opportunities. Migration is sometimes perceived as having different disruptive effects on family-related behaviour. These effects may be reflected in the circumstances that stimulate 
divorce, but they can also be conceived of as disruptions that tend to postpone the process of forming a marriage in the first place.

This section mainly focused on research designs that deal with marriage and divorce. However, this represents only a subset of a larger set of family demographic research designs that could be used to include migrants in studies that examine patterns of leaving the parental home, non-marital union formation and dissolution, non-marital childbearing, re-partnering, step-family formation, and other complex family arrangements (Thomson 2014). Migrants sometimes come from regions with much more complex or dynamic family systems than those in their new destination. This is, for example, the case for migrants from sub-Saharan Africa to Europe, or from Sweden to Spain; or the other way around, such as for migrants from familialistic contexts in Europe, such as Italy or Poland, to less familialistic contexts, such as France or Norway (e.g., Andersson et al. 2017b). Migrants experience family changes that take place in their own life courses, which are, in turn, embedded in larger processes of family change in both their regions of origin and their regions of destination.

\section{MIGRATION AND FERTILITY}

Many parts of Europe are characterised by below-replacement fertility and the prospect of population decline. In such contexts, immigrants may counteract the process of population ageing with their relatively young age structures. They can also contribute to population growth by having relative fertility rates that are higher than those of the ancestral populations in their destination countries. These possibilities have caused demographers to become interested in the fertility of migrants (Sobotka 2008), and help explain why research on migrant fertility is a relatively popular topic in European family demography. However, contrary to expectations, there is little evidence that the fertility patterns of immigrants have led to sustainably elevated fertility rates. When fertility patterns are studied with proper longitudinal data and relevant analytical techniques, the findings tend to indicate that within a short time after arrival, most groups of immigrants display fertility patterns that are remarkably similar to those that prevail in their respective destination contexts. Despite the considerable variation in marriage and divorce patterns among immigrants reported above, far fewer differences are found in the fertility behaviour of different groups of immigrants (for instructive examples based on data from Sweden, see Andersson and Scott 2005, 2007). In the lives of couples and individuals, the decision to have a child is far less reversible than the decision to marry. In most European contexts, childbearing decisions have more long-term, material, and practical consequences in the life courses of the people involved. The decision about whether to have a child may be more affected by structural factors in society and individuals' life circumstances, while decisions on civil status events may be more subject to the influence of different ideological and subjective factors among individuals and their networks.

A crucial reason why migrants rarely bring any high-fertility behaviour to their new contexts of residence, apart from that produced by their youthful age structures, is that there are few migration-sending contexts that still have high-fertility regimes. Except in sub-Saharan Africa, the worldwide demographic transition is about to come to its end. Most regions outside of Europe, just as all countries within this continent, currently have demographic regimes with replacement or below-replacement level fertility. The impact of these changes has been observed in the United States (Frank and Heuveline 2005), where the claim that Mexican 
migrants bring culturally based high-fertility behaviour to the North is called into question by the fact that aggregate fertility in Mexico is no longer visibly higher than that of the United States. Similar arguments can be made for most migrant-sending regions that are located close to Europe, which once had relatively high fertility, but now have fertility levels that hardly differ from those in Northern and Western Europe. This is the case for key migration-sending areas such as Turkey, Iran, and North Africa.

From a sociological and social science point of view, there are many reasons why the study of immigrant fertility is an interesting field of research. It has the potential to provide information on processes of social integration, as migrants' childbearing behaviour is prone to change over time as their locations and life situations change. Clearly, it is equally instructive to study migrants who move from a high- to a low-fertility setting (e.g., Milewski 2007; Dubuc 2012) as it is to study those who move from a low- to a less low-fertility context (e.g., Hwang and Saenz 1997; Okun and Kagya 2012; Tønnessen and Mussino 2020; Mussino et al. 2020). The study of migrants from low-fertility settings has the potential to reveal some of the reasons for the unrealised fertility intentions (Beaujouan and Berghammer 2019) in the migrants' countries of origin; and, perhaps, to shed light on the logics of the low and lowest-low fertility levels of many regions in Europe. When people change their residential and social contexts in the course of their lives, it may be possible to disentangle the roles of current structural factors from those of cultural background in childbearing behaviour. As we stated above, with its diversity in institutional and social settings, Europe represents the ideal research laboratory for any comparative fertility research design.

\section{DATA, METHODS, AND CHALLENGES FOR RESEARCH}

\subsection{Fertility of Migrants}

Data on fertility are based on events that happen only a few times in most peoples' lives - or not at all. These data are sometimes aggregated to summary statistics for a given country or population sub-group. The most common fertility metric is the total fertility rate (TFR). The period TFR is constructed by summing the age-specific fertility rates of women aged 15 to 49 for a certain calendar year. It can also be calculated for a birth cohort of women who are followed over their reproductive career to provide a summary measure when that cohort has reached age 49 . The period TFR is the most common summary statistic on fertility, as it provides an up-to-date and seemingly intuitive measure of childbearing outcomes (see Figure 16.1). However, the TFR is not a very good measure when the aim is to study individual behaviour; in this case, researchers have to rely on longitudinal life course data and suitable regression techniques. The TFR is particularly ill suited when applied to migrants in a given country; TFR statistics often provide inflated numbers on the childbearing outcomes of immigrants. This is because migration, family formation, and childbearing are often interrelated events. Migration, whether international or domestic, frequently occurs in relation to family formation. In situations like this, it is much more common to first make the move and then have a (first) child than the other way around. This sequencing of events produces elevated fertility rates in the regions where immigrants are located. Nobody can be an immigrant until after he or she has migrated, and the fertility rates of immigrants in a given context are thus calculated based only on a post-migration sub-section of their life courses. Research based 
on longitudinal data has shown that the fertility rates of immigrants are elevated in the period immediately following migration, and that their childbearing intensities are later moderated. Thus, when the fertility of migrants is examined over longer periods, fewer differences in fertility are found between immigrant and native populations (e.g., Andersson 2004; Toulemon 2004; Milewski 2007; Parrado 2011).

Research based on longitudinal life course data has the potential to uncover some of the forces that underlie the elevated or depressed fertility of a given group of migrants. Early life socialisation in the migrants' countries of origin may contribute to their relatively high or low fertility. For example, some migrants were socialised in a context that values large families, while others were not. When migrants are exposed to a new context, they may adapt their fertility behaviour to the prevailing behaviour in their destination. This may occur through a process of acculturation in which migrants change their family behaviour norms, or through a process of adaptation in which migrants adapt their behaviour to the structural constraints that provide incentives or disincentives for having children in the new context. The close association between migration and family formation tends to produce elevated fertility in the period shortly after migration. On the other hand, this process may produce a disruption in childbearing behaviour immediately before the migration occurs. If none of these factors provides satisfactory explanations for the empirical findings, the researcher may argue that the selectivity of migrants from a given context contributes to outcomes that differ from those that are prevalent in the country of origin, as well as in the country of destination. Most publications on immigrant fertility provide an overview of these competing but not mutually exclusive hypotheses on selection, socialisation, adaptation, disruption, and the interrelation of events (for overviews, see Kulu 2005; Kulu and González-Ferrer 2014).

\subsection{Data Challenges in Migration Research}

Evidently, there is a wide array of theoretical approaches, analytical designs, and methodological techniques to consider when conducting empirical research on the family behaviour of migrants. The main focus of this contribution has been on issues to consider when attending to life course research on migrants and their family behaviour based on longitudinal data. In this case, the researcher has to deal with dimensions of both space and time. When performing life course research in general, it is essential to track time-varying data with information on changes in characteristics and the occurrence of life events as they evolve over time in the life course. Ideally, researchers would have access to data that also cover all relevant spatial dimensions of such processes. There are a few examples of multi-location studies with information on migrants and non-migrants in both their origins and their (re-)current destinations (e.g., Singley and Landale 1998; Baykara-Krumme and Milewski 2017; Kraus 2019). However, in most cases, the researcher is confined to using data that cover one geographical entity only, and to observing migrants in their current region of residence. This poses some challenges that are specific to research on migrants. The researcher has to deal with issues of left- and right-censoring to properly start and stop any analyses at the time of immigration and any subsequent re-migration, and consider the influences of entry and exit selection in the interpretations of empirical findings based on longitudinal data on migrants. We have already discussed how the interrelation of migration, family formation, and becoming a parent may contribute to artificially high levels of immigrant fertility when these events are summarised based on aggregated data only. Similar 'migration effects' may produce misleading conclu- 
sions on immigrants' mortality. If some migrants are prone to move back to their country of origin in anticipation of poor health, many deaths will be recorded in the origin, and the mortality rates for a given group of immigrants in their assigned destination will appear artificially low; see Andersson and Drefahl (2017) for evidence of such 'salmon effects' in migrant mortality in Sweden.

Many family demographic studies are based on retrospective data consisting of information on migrants and on the events that occurred also prior to immigration. The latter type of data may be valuable as background information on the events and processes that are observed after migration has occurred. However, such data are not suitable for performing longitudinal analyses of the processes that occurred prior to migration. This is because these data do not represent any real-world population in the migrants' country of origin: a migrant is not a migrant until a migration has occurred. Hoem (2014) and Hoem and Nedoluzhko (2016) discussed the many pitfalls and biases that occur in studies that try to build on negative durations (since migration) in pre-migration spells, and the conditioning on the future that is attached to such anticipatory logics.

As we mentioned above, different approaches and analytical designs may produce different conclusions about immigrants and their family demographic behaviour. Different statistical metrics provide information on the tempo and quantum of family demographic outcomes. Some metrics are suitable for providing information on the timing of specific events in the life course, while other metrics are more suitable for providing information on the current or ultimate number of accumulated events. One way to avoid the many challenges of left- and right-censoring in research on migrant fertility is to focus on the completed fertility at the end of the reproductive career (e.g., Wilson 2019). Another strategy is to focus on immigrants who arrived as children (e.g., Mussino et al. 2020), as this avoids the various issues of left-censoring that need to be considered when migration events at adult ages are interrelated with those of family formation.

There may also be differences between countries in which individuals are considered migrants, and should thus be included in different studies on the family behaviour of migrants. At first glance, this may seem to be a trivial point, as a migrant is readily defined as a person who originates in a country or region other than the one in which he or she currently lives. Many statistical agencies produce statistics on foreign-born individuals; i.e., on immigrants. However, many countries also use other concepts in their approaches to tracing migrants and national minorities. Different concepts of ethnicity, race, citizenship, nationality, national minority, and ancestral natives are applied in statistics in different countries, and sometimes make comparative research on minority populations difficult. We have already considered the concept of the 'second generation', which refers to people who are not migrants themselves, but whose parents migrated. In some cases, the second or any subsequent generation of people with a migration background through their parents may develop into and become considered an ethnic minority in a given country. This phenomenon is also reflected in fertility research, which sometimes applies concepts from migration to the study of ethnic minorities in general (e.g., Kulu and Hannemann 2016). It has been argued that minority status can contribute to low fertility, as a focus on social mobility may cause individuals to compromise their fertility desires for the sake of their socio-economic advancement (Goldscheider and Uhlenberg 1969). 


\section{CONCLUSIONS AND DIRECTIONS FOR FUTURE RESEARCH}

As this contribution makes clear, research on the family behaviour of migrants is a still largely untapped reservoir of opportunities with the capacity to produce entirely new insights into a wide array of research topics. The differential speeds and directions of behavioural change in relation to marriage, childbearing, and divorce that have been observed among different types of migrants, and across and within migrant generations, have yet to be explained. Previous research on the family behaviour of migrants has been heavily biased towards a focus on immigrants from contexts with relatively high fertility, and on women. Future research needs to pay equal attention to migrants from low- and high-fertility settings, and to men as well as women. Some researchers have found it useful to focus on migrants who arrived in their destination during childhood: this 1.5 generation of migrants may provide insights into the role of early life socialisation in different contexts, depending on the age at migration (Adserà et al. 2012; Mussino et al. 2020). Patterns of residential segregation and the scope for segmented assimilation may be particularly relevant for this generational category (Wilson and Kuha 2017). Practically every research design with a focus on migrants in Europe has the capacity to benefit from the rich contextual variation in European societies, and in the societies from which migrants in Europe originate.

As a final remark, it is imperative for family demographic research to pay equal attention to the life course careers of women and men. This holds for family research in general, and for family demographic research on migrants in particular. Clearly, previous research has lost many opportunities to gain a better theoretical understanding of different aspects of the gendered dimensions of family demographic behaviour by focusing too much, or exclusively, on women. In the case of migrants, such a gender bias is even more detrimental. Gaining a proper understanding of how the different processes of migration, family formation, and childbearing are interlinked requires a more thorough consideration of the sometimes different spatial and temporal logics of the life course dynamics of male and female migrants. Focusing on both sexes will provide improved insights into the dynamics of gendered interactions in couples and between single individuals, and into how these dynamics may change in the wake of migration.

\section{ACKNOWLEDGEMENTS}

The author acknowledges financial support from the Swedish Research Council for Health, Working Life and Welfare (FORTE), grant number 2016-07105, as well as from the European Research Council under the Horizon 2020 research and innovation programme, grant number 834103.

\section{REFERENCES}

Adserà, A., A.M. Ferrer, W. Sigle-Rushton, and B. Wilson (2012), 'Fertility patterns of child migrants: Age at migration and ancestry in comparative perspective', Annals of the American Academy of Political and Social Science, 643 (1), 160-89. doi:10.1177/0002716212444706.

Andersson, G. (2004), 'Childbearing after migration: Fertility patterns of foreign-born women in Sweden', International Migration Review, 38 (2), 747-75. doi:10.1111/j.1747-7379.2004.tb00216.x. 
Andersson, G. and S. Drefahl (2017), 'Long-distance migration and mortality in Sweden: Testing the salmon bias and healthy migrant hypotheses', Population, Space and Place, 23 (4), e2032. doi:10 $.1002 /$ psp. 2032 .

Andersson, G. and K. Scott (2005), 'Labour-market status and first-time parenthood: The experience of immigrant women in Sweden, 1981-97', Population Studies, 59 (1), 21-38. doi:10.1080/ 0032472052000332683.

Andersson, G. and K. Scott (2007), 'Childbearing dynamics of couples in a universalistic welfare state: The role of labor-market status, country of origin, and gender', Demographic Research, 17 (30), 897-938. doi:10.4054/DemRes.2007.17.30.

Andersson, G., O. Obućina, and K. Scott (2015), 'Marriage and divorce of immigrants and descendants of immigrants in Sweden', Demographic Research, 33 (2), 31-64. doi:10.4054/DemRes.2015.33.2.

Andersson, G., L. Persson, and O. Obućina (2017a), 'Depressed fertility among descendants of immigrants in Sweden', Demographic Research, 36 (39), 1149-84. doi:10.4054/DemRes.2017.36.39.

Andersson, G., E. Thomson, and A. Duntava (2017b), 'Life-table representations of family dynamics in the 21st century', Demographic Research, 37 (35), 1081-230. doi:10.4054/DemRes.2017.37.35.

Bachrach, C. (2014), 'Culture and Demography: From reluctant bedfellows to committed partners', Demography, 51, 3-25. doi:10.1007/s13524-013-0257-6.

Baykara-Krumme, H. and N. Milewski (2017), 'Fertility patterns among Turkish women in Turkey and abroad: The effects of international mobility, migrant generation, and family background', European Journal of Population, 33 (3), 409-36. doi:10.1007/s10680-017-9413-9.

Beaujouan, E. and C. Berghammer (2019), 'The gap between lifetime fertility intentions and completed fertility in Europe and the United States: A cohort approach', Population Research and Policy Review, 38, 507-35. doi:10.1007/s11113-019-09516-3.

Bledsoe, C. (2004), 'Reproduction at the margins: Migration and legitimacy in the New Europe', Demographic Research, Special Collection 3, 85-116. doi:10.4054/DemRes.2004.S3.4.

Boyd, M. (1989), 'Family and personal networks in international migration: Recent developments and new agendas', International Migration Review, 23 (3), 638-70. doi:10.1177/019791838902300313.

Castles, S., H. de Haas, and M. Miller (2013), The Age of Migration: International Population Movements in the Modern World, 5th edition, New York: Guilford Press.

Cherlin, A. (2009), The Marriage-Go-Round: The State of Marriage and the Family in America Today, New York: Alfred Knopf.

Dribe, M. and C. Lundh (2011), 'Cultural dissimilarity and intermarriage. A longitudinal study of immigrants in Sweden 1990-2005', International Migration Review, 45 (2), 297-324. doi:10.1111/j .1747-7379.2011.00849.x.

Dubuc, S. (2012), 'Immigration to the UK from high-fertility countries: Intergenerational adaptation and fertility convergence', Population and Development Review, 38 (2), 353-68. doi:10.1111/j $.1728-4457.2012 .00496 . x$.

Frank, R. and P. Heuveline (2005), 'A crossover in Mexican and Mexican-American fertility rates: Evidence and explanations for an emerging paradox', Demographic Research, 12 (4), 77-104. doi:10 .4054/DemRes.2005.12.4.

Glick, J. (2010), 'Connecting complex processes: A decade of research on immigrant families', Journal of Marriage and Family, 72 (3), 498-515. doi:10.1111/j.1741-3737.2010.00715.x.

Goldscheider, C. and P. Uhlenberg (1969), 'Minority group status and fertility', American Journal of Sociology, 74, 361-72.

Goode, W. (1963), World Revolution and Family Patterns, New York: Free Press.

Goode, W. (1993), World Changes in Divorce Patterns, New Haven, CT: Yale University Press.

Goody, J. (1983), The Development of the Family and Marriage in Europe, Cambridge: Cambridge University Press.

Haandrikman, K. (2014), 'Binational marriages in Sweden: Is there an EU effect?', Population, Space and Place, 20 (2), 177-99. doi:10.1002/psp.1770.

Hannemann, T., H. Kulu, A. González-Ferrer, A. Pailhé, L. Rahnu, and A. Puur (2020), 'Partnership dynamics among immigrants and their descendants in four European countries', Population, Space and Place, 26 (5), e2315. doi:10.1002/psp.2315.

Hoem, J.M. (2014), 'The dangers of conditioning on the time of occurrence of one demographic process in the analysis of another', Population Studies, 68 (2), 151-9. doi:10.1080/00324728.2013.843019. 
Hoem, J.M. and L. Nedoluzhko (2016), "The dangers of using "negative durations" to estimate pre- and post-migration fertility', Population Studies, 70 (3), 359-63. doi:10.1080/00324728.2016.1221442.

Hwang, S.-S. and R. Saenz (1997), 'Fertility of Chinese immigrants in the US: Testing a fertility emancipation hypothesis', Journal of Marriage and the Family, 59 (1), 50-61. doi:10.2307/353661.

Kahn, J. (1988), 'Immigrant selectivity and fertility adaptation in the United States', Social Forces, 67 (1), 108-28. doi:10.1093/sf/67.1.108.

Kraus, E. (2019), 'Family formation trajectories across borders: A sequence analysis approach to Senegalese migrants in Europe', Advances in Life Course Research, 42. doi:10.1016/j.alcr.2019 .100290 .

Kulu, H. (2005), 'Migration and fertility: Competing hypotheses re-examined', European Journal of Population, 21, 51-87. doi:10.1007/s10680-005-3581-8.

Kulu, H. and A. González-Ferrer (2014), 'Family dynamics among immigrants and their descendants in Europe: Current research and opportunities', European Journal of Population, 30, 411-35. doi:10 $.1007 / \mathrm{s} 10680-014-9322-0$.

Kulu, H. and T. Hannemann (2016), 'Why does fertility remain high among certain UK-born ethnic minority women?', Demographic Research, 35 (49), 1441-88. doi:10.4054/DemRes.2016.35.49.

Kulu, H., T. Hannemann, A. Pailhé, K. Neels, S. Krapf, A. González-Ferrer, and G. Andersson (2017), 'Fertility by birth order among the descendants of immigrants in selected European countries', Population and Development Review, 43 (1), 31-60. doi:10.1111/padr.12037.

Lee, E. (1966), 'A theory of migration', Demography, 3, 47-57.

Massey, D., J. Arango, G. Hugo, A. Kouaouci, A. Pellegrino, and J.E. Taylor (1993), 'Theories of international migration: A review and appraisal', Population and Development Review, 19, 431-66. doi: $10.2307 / 2938462$.

Milewski, N. (2007), 'First child of immigrant workers and their descendants in West Germany: Interrelations of events, disruption, or adaptation?', Demographic Research, 17 (29), 859-96. doi:10 .4054/DemRes.2007.17.29.

Murphy, M. (2016), 'The impact of migration on long-term European population trends, 1850 to present', Population and Development Review, 42 (2), 225-44. doi:10.1111/j.1728-4457.2016.00132.x.

Mussino, E., B. Wilson, and G. Andersson (2020), 'The fertility of immigrants from low fertility settings: Adaptation in the tempo and quantum of childbearing?', Stockholm Research Reports in Demography, 22. doi:10.17045/sthlmuni.12367583.v2.

Notestein, F. (1945), 'Population: The long view', in T. Schultz (ed.), Food for the World, Chicago, IL: University of Chicago Press.

Okun, B. and S. Kagya (2012), 'Fertility change among post-1989 immigrants to Israel from the former Soviet Union', International Migration Review, 46 (4), 792-827. doi:10.1111/imre.12001.

Parrado, E. (2011), 'How high is Hispanic/Mexican fertility in the United States? Immigration and tempo considerations', Demography, 48 (3), 1059-80. doi:10.1007/s13524-011-0045-0.

Portes, A., P. Fernández-Kelly, and W. Haller (2005), 'Segmented assimilation on the ground: The new second generation in early adulthood', Ethnic and Racial Studies, 28 (6), 1000-40. doi:10.1080/ 01419870500224117.

Singley, S. and N. Landale (1998), 'Incorporating origin and process in migration-fertility frameworks: The case of Puerto Rican women', Social Forces, 76 (4), 1437-70. doi:10.2307/3005841.

Sobotka, T. (2008), 'The rising importance of migrants for childbearing in Europe', Demographic Research, 19 (9), 225-48. doi:10.4054/DemRes.2008.19.9.

Thomson, E. (2014), 'Family complexity in Europe', Annals of the American Academy of Political and Social Science, 654 (1), 245-58. doi:10.1177/0002716214531384.

Tønnessen, M. and E. Mussino (2020), 'Fertility patterns of migrants from low-fertility countries in Norway', Demographic Research, 42 (31), 859-74. doi:10.4054/DemRes.2020.42.31.

Toulemon, L. (2004), 'Fertility among immigrant women: New data, a new approach', Population and Societies, 400, 1-4.

Wilson, B. (2019), 'The intergenerational assimilation of completed fertility: Comparing the convergence of different origin groups', International Migration Review, 53 (2), 429-57. doi:10.1177/ 0197918318769047.

Wilson, B. and J. Kuha (2017), 'Residential segregation and the fertility of immigrants and their descendants', Population, Space and Place, 24 (3), e2098. doi:10.1002/psp.2098.

World Bank (2019), World Bank Open Data, accessed 14 October 2019 at www.data.worldbank.org. 